\title{
Ciclesonide improves measures of small airway involvement in asthma
}

\author{
J. Cohen*, W.R. Douma*, N.H.T. ten Hacken*, J.M. Vonk", \\ M. Oudkerk and D.S. Postma*
}

ABSTRACT: Ciclesonide is delivered as a small-particle inhaled corticosteroid and improves lung function and airway hyperresponsiveness. The objective of the present study was to assess whether ciclesonide can specifically improve small airway function in asthma.

A total of 16 mild-to-moderate asthma patients (seven males; median (range) age 39 (19-56) yrs and forced expiratory volume in one second (FEV 1$) 89(62-120) \%$ predicted) were randomised to 5 weeks' treatment with placebo or $320 \mu \mathrm{g}$ ciclesonide once daily. The following small airway parameters were assessed: mean forced expiratory flow between 25 and $75 \%$ of forced vital capacity (FVC), percentage fall in FVC at provocative dose of adenosine-5'-monophosphate and of methacholine $(\mathrm{MCh})$ causing a $20 \%$ fall in $\mathrm{FEV}_{1}$, expiratory lung volume on computed tomography (CT) scan after MCh challenge, single-breath nitrogen closing volume and alveolar exhaled nitric oxide (eNO).

Seven subjects received placebo and nine received ciclesonide. Both alveolar eNO and CT measurements of expiratory lung volume after $\mathrm{MCh}$ challenge decreased significantly with ciclesonide (median (range) decrease 4.4 (54.8-1.4) ppb and 59 (1,569- -117) $\mathrm{mL}$, respectively), and compared with placebo (-0.4 (7.3- -3.4) ppb and -121 (20- -236) $\mathrm{mL}$ respectively). Ciclesonide did not significantly improve other small airways parameters.

Inflammation and patency of small airways, reflected by alveolar exhaled nitric oxide and air trapping on computed tomography scan, both improve with ciclesonide even in this small number of patients. This indicates that ciclesonide exerts anti-inflammatory effects on small airways.

KEYWORDS: Asthma, ciclesonide, small airways

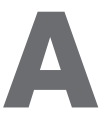

sthma is a chronic inflammatory disease of the airways and anti-inflammatory treatment with inhaled corticosteroids (ICS) constitutes the cornerstone of asthma management. Nevertheless, a considerable subset of asthma patients does not benefit from ICS or gain optimal asthma control [1-3]. It can be speculated that inflammation of the small airways contributes to the poor asthma control observed, since small airways are not directly reached by conventional ICS [4].

The small airways, i.e. airways with an internal diameter $<2 \mathrm{~mm}$, have not always been considered important in asthma. After having been dubbed 'the quiet zone' by MEAD et al. [5] because they contributed merely $10 \%$ to total airway resistance, the small airways have regained attention over the past $15 \mathrm{yrs}$ due to their role in asthma. At present, it is acknowledged that increasing physiological and pathological evidence exists that inflammation of the small airways is similarly and often even more pronounced than in larger airways in severe asthma $[6,7]$. This new insight in the importance of small airway inflammation in asthma has led to the introduction of ICS with small-particle formulations that target this site of inflammation. Ciclesonide (Alvescon; Nycomed BV, Hoofddorp, the Netherlands) is such an ICS, as it is formulated as a solution delivered via a hydrofluoroalkane134a metered-dose inhaler. A labelling study showed that a high fraction of ciclesonide (52\%) is deposited in the lung. Additionally, threedimensional single photon emission computed tomography (3D SPECT) analysis revealed that the highest ciclesonide deposition was found in peripheral regions of the lung, i.e. the zones with small airways and alveoli [8].

Ciclesonide has been demonstrated to maintain asthma control [9] and improve lung function
AFFILIATIONS

Depts of *Pulmonology,

\#Epidemiology, and

'Radiology, University Medical Center Groningen, University of Groningen, Groningen, the Netherlands.

CORRESPONDENCE

D.S. Postma

Dept of Pulmonology UMCG

P0 Box 30001

9700 RB Groningen

The Netherlands

Fax: 31503619320

E-mail: d.s.postma@int.umcg.nl

Received:

July 042007

Accepted after revision:

February 042008

CLINICAL TRIAL

The present study is registered at clinicaltrials.gov (identifier NCT00163345).

STATEMENT OF INTEREST Statements of interest for D.S. Postma and the study itself can be found at www.erj.ersjournals.co.uk/ misc/statements.shtml 
(forced expiratory volume in one second (FEV1), peak expiratory flow and forced vital capacity (FVC)) in both mild-to-moderate and moderate-to-severe asthma [10]. Furthermore, ciclesonide reduces symptoms and airway hyperresponsiveness assessed with both methacholine (MCh) [11] and adenosine-5'-monophosphate (AMP) [12, 13].

Although it is known that ciclesonide improves lung function and inflammation [14-17], it is still unknown whether it specifically improves small airway function and inflammation. It has been demonstrated that ciclesonide reaches the small airways [8], therefore it can be hypothesised that ciclesonide improves small airway parameters in asthma. In order to determine the efficacy of ciclesonide, different parameters of small airway function and inflammation were evaluated in 16 mild-to-moderate asthma patients in a double-blind randomised, placebo-controlled pilot trial with $320 \mu \mathrm{g}$ ciclesonide, once daily.

\section{MATERIALS AND METHODS \\ Subjects}

Subjects were recruited from the outpatient clinic of the Dept of Pulmonology (University Medical Center Groningen, Groningen, the Netherlands) and by advertisements in local papers. The local medical ethics committee reviewed and approved the study protocol, and the study was registered in a public trial database (clinicaltrials.gov identifier NCT00163345). All subjects gave their written informed consent.

\section{Inclusion criteria}

Subjects of either sex, between 18 and 60 yrs of age, with a history of asthma according to the Global Initiative for Asthma criteria [18] and using $<800 \mu \mathrm{g} \cdot \mathrm{day}^{-1}$ of budesonide or equivalent were eligible for study participation. In addition, subjects were required to have: a baseline FEV1 $\geqslant 60 \%$ predicted [19]; bronchial responsiveness, defined as a provocative concentration causing a $20 \%$ fall in FEV1 from baseline (PC20), to both $\mathrm{MCh}$ and AMP of $\leqslant 4.9 \mathrm{mg} \cdot \mathrm{mL}^{-1}$ and $\leqslant 40 \mathrm{mg} \cdot \mathrm{mL}^{-1}$, respectively; and proven atopy defined by at least one positive skin prick test to 18 common aeroallergens.

\section{Exclusion criteria}

Current smokers or ex-smokers with cessation of smoking $<1$ yr prior to study participation or with $>10$ pack-yrs were excluded. In addition, subjects were not eligible if they had: 1) a history of chronic obstructive pulmonary disease (COPD) or other pulmonary or concomitant diseases expected to interfere with the study; 2) unstable asthma (defined as more than three exacerbations in the previous year or one exacerbation in the previous 2 months); 3) concomitant medication that was not allowed (e.g. oral corticosteroids within 4 weeks prior to study participation); 4) intolerance for short-acting $\beta_{2}$-agonists (SABA) or suspected hypersensitivity for ICS; or 5) females who were pregnant, lactating or lacking an effective method of contraception.

\section{Study design}

The present pilot study was designed as a double-blind, randomised, placebo-controlled, parallel-group trial (a schematic of the study is shown in figure 1). The study consisted of a 4-week pre-baseline period, for those pre-treated with ICS with or without a long-acting $\beta_{2}$-agonist (LABA), followed by a 2-3-week baseline period and a 5-6-week treatment period, depending on whether a bronchoscopy was performed. Treatment with ICS or LABA was withdrawn during the prebaseline period and substituted with SABA only as rescue medication. Subjects who were treated with SABA only as rescue medication and who had an FEV1 $\geqslant 60 \%$ pred entered the study in the baseline period. After the 2-3-week baseline period, subjects demonstrating bronchial responsiveness to both MCh and AMP were randomised in order to receive either ciclesonide $320 \mu \mathrm{g}$ once daily or placebo in the morning for 5-6 weeks. Randomisation was stratified for pre-treatment with or without ICS.

\section{Small airways parameters}

Alveolar exhaled nitric oxide fraction

Endogenous nitric oxide production is increased in asthma due to inflammation of airway epithelium [20]. Measurement of alveolar exhaled nitric oxide (eNO) reflects inflammation in small airways [21].

At two baseline visits, 1 week apart, and after treatment, eNO was measured at multiple flow rates $\left(30 \mathrm{~mL} \cdot \mathrm{s}^{-1}, 50 \mathrm{~mL} \cdot \mathrm{s}^{-1}\right.$, $100 \mathrm{~mL} \cdot \mathrm{s}^{-1}$ and $200 \mathrm{~mL} \cdot \mathrm{s}^{-1}$ ) using a NIOX (Aerocrine, Stockholm, Sweden). The mean eNO value (in $\mathrm{ppb}$ ) of three technically acceptable attempts per flow rate was used for analysis. Alveolar eNO fraction (ppb) as well as the bronchial nitric oxide flux $\left(\mathrm{nL} \cdot \mathrm{s}^{-1}\right)$ were calculated with a modification of the two-compartment model of nitric oxide exchange [22]. The test was performed on two occasions to train subjects in performing eNO tests correctly. The eNO values acquired during the third baseline visit (day 9) were used to analyse treatment effects.

\section{Air trapping on expiratory computed tomography scan}

Quantitative image analysis of computed tomography (CT) scans were performed at end-expiration (near residual volume (RV) level), both before and after bronchoprovocation, which reflects regional air trapping due to small airways obstruction $[23,24]$.

An inspiratory CT scan was acquired during a 10-s breathhold at full inspiration (near total lung capacity) at baseline. This was followed by a CT scan during a 10-s breathhold at end expiration, which approximates RV. Subsequently, an MCh

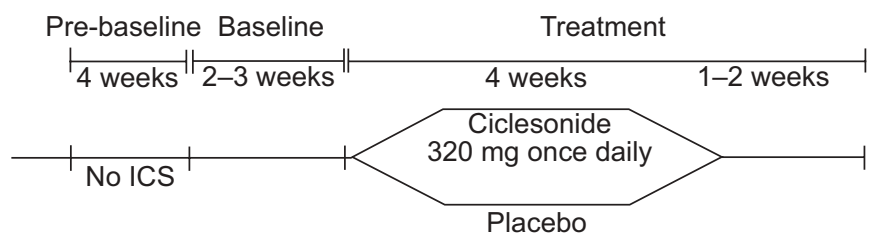

FIGURE 1. Schematic of the study design. During the baseline period, the procedures performed were as follows. Day 1: exhaled nitric oxide (eNO), singlebreath nitrogen test $\left(\mathrm{SBN}_{2}\right)$ and methacholine $(\mathrm{MCh})$ challenge; day 2: adenosine5'-monophosphate challenge; day 9: eNO, $\mathrm{SBN}_{2}, \mathrm{MCh}$ challenge and computed tomography (CT) scan; and day 16: bronchoscopy. During the final 1-2 weeks of the treatment period, the procedure performed were as follows. Day 44: eNO, $\mathrm{SBN}_{2}$, MCh challenge and CT scan; day 45: AMP challenge; and day 52: bronchoscopy. ICS: inhaled corticosteroids. 
provocation was performed on site, again followed by an endexpiratory scan immediately after PC20 of MCh had been reached. After 5 weeks of treatment, an end-expiratory scan after reaching PC20 of $\mathrm{MCh}$ was acquired again. Inspiratory and expiratory manoeuvres were practised twice before the procedure and subjects were coached by a trained technician during scanning in the supine position. All scans were performed on a 16-slice MultiDetector CT (MDCT) scanner (Siemens Somatom Sensation 16; Siemens AG Medical Solutions, Erlangen, Germany) at $120 \mathrm{kVp}, 25 \mathrm{mAs}$ (inspiration) and $30 \mathrm{mAs}$ (expiration), $0.5 \mathrm{~s}$ rotation time. A table feed of $18 \mathrm{~mm} \cdot$ rotation $^{-1}$, and a $1-\mathrm{mm}$ slice thickness with $0.6-\mathrm{mm}$ increment were used. The estimated effective radiation dose was $0.78 \mathrm{mSv}$ for inspiratory scans and $0.94 \mathrm{mSv}$ for expiratory scans.

Anonymised MDCT data were sent to the Center for Medical Diagnostic Systems and Visualisation (MeVis; Bremen, Germany) who was blinded to the intervention. Scan data were analysed by the advanced image analysis software MeVisPULMO3D. A detailed description of the lung segmentation with MeVisPULMO3D software is provided as supplementary data. Based on the segmentation, quantitative volumetric and densitometric analyses were performed of total, right and left lung separately and of each individual lung lobe. The parameters used in this study were volume (in $\mathrm{mL}$ ), mean lung density (MLD; in Hounsfield units (HU)), 15th percentile density (in $\mathrm{HU}$ ), and percentage of low attenuation areas (LAA). LAA were defined at a cut-off point of -950 HU. MCh-induced air trapping on CT was defined at baseline as the absolute change in MLD, 15th percentile density and LAA between the two expiratory scans before and after $\mathrm{MCh}$ challenge. The change in volume between the two expiratory scans before and after MCh challenge was also corrected for inspiratory lung volume by using the following equation:

$\%$ volume change $=100 \times(($ inspiration-expiration $)$-(inspirationexpiration postMCh))/(inspiration-expiration)

Closing volume with single-breath $\mathrm{N}_{2}$ test

Closing volume measured with a single-breath nitrogen $\left(\mathrm{SBN}_{2}\right)$ test reflects air trapping due to small airways obstruction [25, 26]. At two baseline visits, 1 week apart, and after treatment, a $\mathrm{SBN}_{2}$ test was performed (Quark PFT ${ }^{\circledR}$; Cosmed, Rome, Italy). Subjects were coached into tidal breathing, after which they slowly inspired pure oxygen to total lung capacity. Hereafter, they slowly exhaled to RV level, during which the $\mathrm{N}_{2}$ concentration was measured and plotted against lung volume. The slope of the alveolar $\mathrm{N}_{2}$ plateau was calculated by one investigator by drawing the best-fit line through phase III of the expiratory volume-concentration curve. In order to minimise intra-observer variability, one reader measured closing volume $(\mathrm{mL})$ and the slope of the alveolar $\mathrm{N}_{2}$ plateau $\left(\delta \mathrm{N}_{2}\right.$ in $\left.\% \cdot \mathrm{mL}^{-1}\right)$ on one day after all subjects had completed the study. Two measurements were selected for analysis when closing volume differed $<20 \%$ or $100 \mathrm{~mL}$. The mean of both measurements was used for analysis. The $\mathrm{SBN}_{2}$ test was performed on two occasions to train subjects in performing the closing volume manoeuvre correctly. Closing volume and $\delta \mathrm{N}_{2}$ values acquired during the second baseline visit (day 9) were used to analyse treatment effects.

\section{$\triangle \mathrm{FVC} \%$ and $\triangle \mathrm{SVC} \%$ at $\mathrm{PC} 20$ of MCh and $\mathrm{AMP}$}

The percentage fall from baseline in FVC and slow inspiratory vital capacity (SVC) at the time $20 \%$ fall in FEV1 occurred during bronchial hyperresponsiveness testing $(\triangle \mathrm{FVC} \%$ at $\mathrm{PC} 20$ and $\triangle \mathrm{SVC} \%$ at $\mathrm{PC} 20$, respectively), may reflect air trapping due to excessive bronchoconstriction or small airways closure [27, 28].

MCh and AMP challenge testing was performed using the standardised 2-min tidal breathing protocol [29]. Additionally, FVC and SVC were measured in a combined manoeuvre (see online supplementary material) at 30 and $90 \mathrm{~s}$ after each inhaled dose of either MCh or AMP. Spirometry was measured with a daily calibrated dry wedge spirometer (Masterscope; Jaeger, Hoechberg, Germany). Subjects received doubling doses of MCh bromide $\left(0.038-19.6 \mathrm{mg} \cdot \mathrm{mL}^{-1}\right)$ at two baseline visits, 1 week apart, and after treatment (fig. 1). The subjects received doubling doses of AMP $\left(0.04-320 \mathrm{mg} \cdot \mathrm{mL}^{-1}\right)$ at baseline and after treatment. The fall in FVC and SVC $(\triangle \mathrm{FVC} \%$ and $\triangle \mathrm{SVC} \%$ ) at $\mathrm{PC} 20$ was calculated using log-linear interpolation.

Cytokines measured in epithelial lining fluid in peripheral airways The most direct method to assess airway inflammation is via bronchoscopy. The diameter of a bronchoscope is too large to reach the small airways but microsampling probes may reach the peripheral airways [30,31]. The technique and cytokine measurements are described in the online supplementary material.

\section{Statistical analysis}

A Wilcoxon signed-rank test was used to assess withintreatment differences; a Mann-Whitney U-test was used for between-treatment differences (the difference between changes with ciclesonide and placebo treatment). All analyses were considered to be explorative in the absence of a statistical power calculation given the pilot nature of the study.

\section{RESULTS}

\section{Study population}

A total of 16 subjects were randomised to treatment and completed the study, seven subjects received placebo and nine received $320 \mu \mathrm{g}$ of ciclesonide, once daily in the morning. Demographics and lung function at baseline of both groups were not significantly different (table 1 ).

Small airways parameters measured at baseline were also not statistically different between treatment groups (table 2), although higher values were observed in the ciclesonide group as a result of the randomisation of more males to this group.

\section{Treatment effects}

\section{Alveolar eNO}

Median (range) alveolar eNO values were significantly lower after ciclesonide (8.5 (3.7-12.5) ppb) than after placebo (16.5 (5.6-39.6) ppb; $\mathrm{p}=0.012)$. The median decrease in alveolar eNO from baseline with ciclesonide $(4.4 \mathrm{ppb})$ was significantly different from the change from baseline with placebo $(-0.4 \mathrm{ppb}$; $\mathrm{p}=0.006$; fig. 2).

\section{Air trapping on expiratory CT scan}

MCh-induced air trapping at baseline is presented in table E1 in the online supplementary data. 
TABLE 1 Patient characteristics and lung function at baseline and after treatment

\begin{tabular}{|c|c|c|c|c|}
\hline & \multicolumn{2}{|c|}{ Placebo } & \multicolumn{2}{|c|}{ Ciclesonide } \\
\hline & Baseline & Post-treatment & Baseline & Post-treatment \\
\hline Subjects $\mathrm{n}$ & 7 & & 9 & \\
\hline Male & $2(29)$ & & $5(56)$ & \\
\hline Age yrs & $44(21-53)$ & & $36(19-56)$ & \\
\hline FEV $1 /$ FVC $\%$ & 77 (68-88) & 78 (66-83) & $67(52-79)$ & $70(60-83)$ \\
\hline FVC \% pred & $101(84-144)$ & $105(82-141)$ & $115(93-122)$ & $117(96-136)^{\# \cdot 9}$ \\
\hline svC \% pred & $103(82-145)$ & $109(81-145)$ & $112(94-131)$ & $122(98-135)^{\# \cdot \bullet}$ \\
\hline $\mathrm{PC}_{20}$ of $\mathrm{MCh}, \mathrm{mg} \cdot \mathrm{mL}^{-1}$ & $0.4(0.2-4.2)$ & $0.3(0.1-3.6)$ & $0.5(0.1-2.0)$ & $1.3(0.2-39.2)^{\#, \cdot}$ \\
\hline $\mathrm{PC}_{20}$ of $\mathrm{AMP}, \mathrm{mg} \cdot \mathrm{mL}^{-1}$ & $4.8(0.2-23.1)$ & $3.8(0.7-23.4)$ & $4.0(0.2-36.2)$ & $35.1(1.2-640.0)^{\# .9}$ \\
\hline $\mathrm{eNO}$ at $50 \mathrm{~mL} \cdot \mathrm{s}^{-1} \mathrm{ppb}$ & $65(34-204)$ & $83(28-222)$ & 99 (33-281) & $36(17-59)^{\#, 9}$ \\
\hline
\end{tabular}

Data are presented as $\mathrm{n}(\%)$ or median (range), unless otherwise stated. BMI: body mass index; FEV1: forced expiratory volume in one second; \% pred: \% predicted; FVC: forced vital capacity; SVC: slow inspiratory vital capacity; PC20: provocative dose causing a $20 \%$ fall in FEV1; MCh: methacholine; AMP: adenosine-5'monophosphate; eNO: exhaled nitric oxide. ${ }^{\#}: p<0.05$ compared with placebo; ${ }^{"}: p<0.05$ compared with baseline.

Median (range) expiratory lung volume after MCh decreased by $59(1,569--117) \mathrm{mL}$ with ciclesonide and increased by 121 (-20-236) $\mathrm{mL}$ with placebo, although these within-treatment differences were not statistically significantly. The changes in expiratory lung volume, MLD and 15th percentile density on expiratory $\mathrm{CT}$ scan after MCh challenge testing differed significantly between the ciclesonide and placebo group (betweentreatment difference), $p=0.042, p=0.016$ and $p=0.023$, respectively (fig. $3 \mathrm{a}-\mathrm{c}$ ), whereas the change in percentage LAA was of borderline significance $(p=0.055$; fig. $3 d$ ).

Closing volume with $\mathrm{SBN}_{2}$ test

Median closing volume decreased in both the placebo (140$105 \mathrm{~mL}$ ) and ciclesonide group (230-115 mL). These decreases were not statistically significant, both within and between treatment groups (fig. 4).
$\Delta \mathrm{FVC} \%$ and $\triangle \mathrm{SVC} \%$ at $\mathrm{PC}_{20}$ of MCh and at $\mathrm{PC} 20$ of $\mathrm{AMP}$ $\triangle \mathrm{FVC} \%$ and $\triangle \mathrm{SVC} \%$ at $\mathrm{PC}_{20}$ of $\mathrm{MCh}$ and at $\mathrm{PC}_{20}$ of $\mathrm{AMP} \operatorname{did}$ not change significantly with either treatment.

FEF25-75\% \% predicted

Mean forced expiratory flow between 25 and $75 \%$ of forced vital capacity (FEF25-75\%) was measured with spirometry. Median FEF25-75\% \% pred increased in the ciclesonide-treated group from $52-63 \%$, which was of borderline significance $(p=0.051)$. The change with ciclesonide was not significantly different from the change with placebo (table 2).

\section{Secondary parameters}

The mean increase in $\log _{2} \mathrm{PC} 20$ of $\mathrm{MCh}$ was significantly larger with ciclesonide than with placebo, 1.4 versus 0.2 doubling doses, respectively $(\mathrm{p}=0.031)$. The mean increase in $\log _{2} \mathrm{PC} 20$

TABLE 2 Small airway parameters at baseline and after treatment

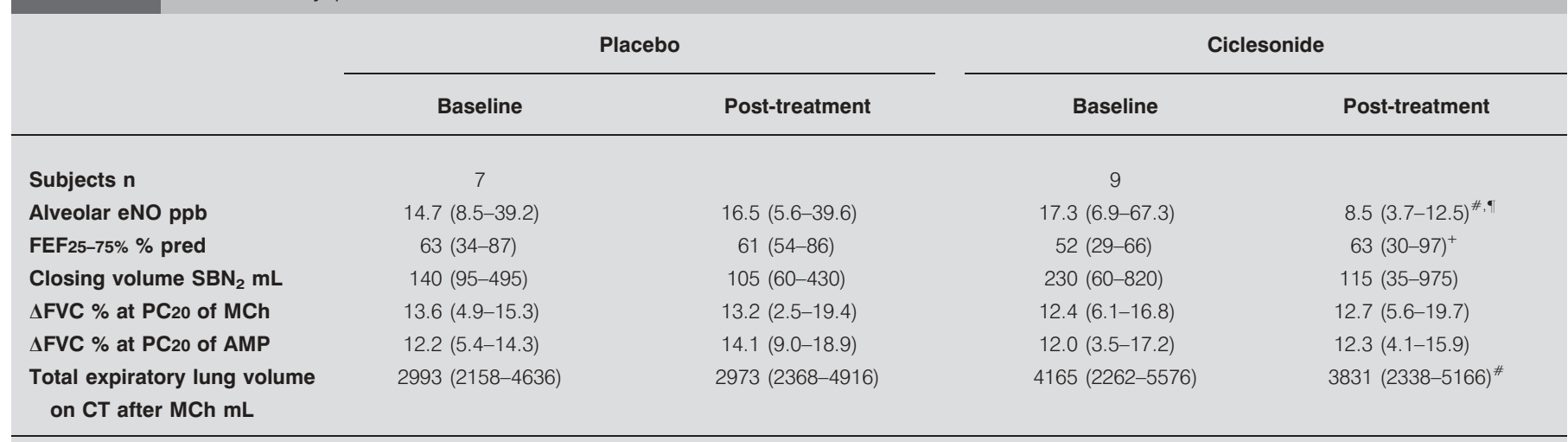

Data are presented as median (range), unless otherwise stated. eNO: exhaled nitric oxide; FEF25-75\%: mean forced expiratory flow between 25 and $75 \%$ of forced vital capacity; $\mathrm{SBN}_{2}$ : single-breath nitrogen test; $\triangle \mathrm{FVC}$ : change in forced vital capacity; $\mathrm{PC} 20$ : provocative dose causing a $20 \%$ fall in forced expiratory volume in one second; MCh: methacholine; AMP: adenosine- $5^{\prime}$-monophosphate; CT: computed tomography. ${ }^{\#}: p<0.05$ compared with placebo; ${ }^{*}: p<0.05$ compared with baseline; ${ }^{+}: p=0.051$ compared with baseline. 


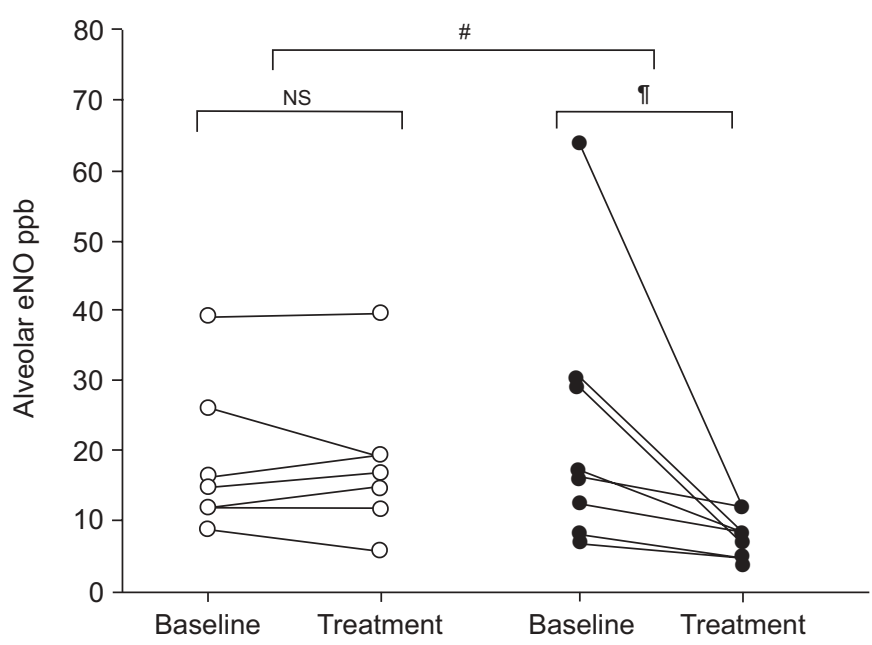

FIGURE 2. Alveolar exhaled nitric oxide (eNO). Alveolar eNO before and after treatment with placebo $(\bigcirc)$ and ciclesonide $(\bullet)$. NS: nonsignificant. ${ }^{*}: p=0.006$ from Mann-Whitney U-test; ${ }^{\bullet}: p=0.012$ from Wilcoxon signed rank test.

of AMP was also significantly larger with ciclesonide than placebo, 2.9 versus 0.3 doubling doses, respectively $(\mathrm{p}=0.029)$. The changes in FEV1 \% pred, FVC \% pred and SVC \% pred were also significantly larger with ciclesonide (median increase of 6,6 and $4 \%$ pred, respectively) than with placebo (median decrease of 2,2 and $1 \%$ pred, and $p=0.003, p=0.003$ and $\mathrm{p}=0.023$, respectively). Bronchial median (range) eNO decreased significantly with ciclesonide $\left(1.4(0.2-5.6) \mathrm{nL} \cdot \mathrm{s}^{-1}\right.$; $\mathrm{p}=0.016)$, significantly more than with placebo $(\mathrm{p}=0.004)$.

Cytokines measured in epithelial lining fluid in peripheral airways Bronchoscopy was performed in seven subjects (two placebo and five ciclesonide). Due to blood contamination in 21 (50\%) out of a total of 42 peripherally placed probes, cytokine measurements of peripherally sampled epithelial lining fluid (ELF) were only possible in one subject in the placebo and two in the ciclesonide group, both at baseline and post-treatment. Thymus and activation-regulated chemokine was not detectable in any of the probes. Other cytokine concentrations in ELF are presented in table E2 of the online supplementary data. Statistical analysis was not performed due to the small sample size.

\section{DISCUSSION}

The present pilot study demonstrates that treatment with $320 \mu \mathrm{g}$ ciclesonide once daily can specifically improve parameters reflecting inflammation and patency of the small airways, even in a small sample of 16 patients with mild-tomoderate asthma. Earlier studies have already shown the efficacy of ciclesonide in maintaining asthma control and in reducing symptoms and airway hyperresponsiveness [9-13, $16,17,32-36]$. The present study confirms and extends these observations in that ciclesonide also exerts anti-inflammatory effects on small airways. The present study has demonstrated the beneficial effects of the small-particle ICS, ciclesonide, on small airway involvement in asthma compared with placebo. Further studies are needed to evaluate whether treatment with this small-particle ICS is superior to treatment with a largeparticle ICS, with respect to small airway involvement, symptoms and control of asthma. If so, the importance of
ICS distribution throughout the whole lung must be acknowledged when treating patients who do not gain optimal asthma control with conventional large-particle ICS.

The present study is the first to assess the effects of ciclesonide on small airway parameters. VERBANCK et al. [37] demonstrated beneficial effects of small-particle ICS on acinar lung zone abnormalities in asthma but did not compare these effects with placebo. HAUBER et al. [38] previously demonstrated beneficial effects of a small-particle ICS on peripheral airways by a reduction of eosinophilic inflammation in transbronchial biopsies and an increase in FEF25-75\% \% pred. In a study from the same group, signs of airway remodelling were reduced, thus demonstrating direct effects of a small-particle ICS on peripheral airway inflammation, remodelling and airway function [39]. Nevertheless, transbronchial biopsies are not easily applicable in clinical practice due to their invasive nature. In a less invasive manner, large- and small-particle ICS were investigated for effects on small airways by assessing MCh-induced air trapping on expiratory HRCT scans in mildto-moderate asthma. The small-particle ICS improved MChinduced air trapping significantly more than the large-particle ICS, indicating a direct effect of the former on the small airways [40]. Consistent with these results, ZEIDLER et al. [23] demonstrated that montelukast (leukotriene receptor antagonist) reduced $\mathrm{MCh}$-induced air trapping on expiratory $\mathrm{CT}$ scans in mild-to-moderate asthma, in association with improved quality of life. However, other parameters of small airway dysfunction, such as closing volume $\left(\mathrm{SBN}_{2}\right.$ test), were not related to the montelukast-induced reduction of air trapping [23]. The present study confirms that treatment with a small-particle ICS significantly reduces $\mathrm{MCh}$-induced air trapping due to small airway closure. Additionally, the present authors found the effects of the small-particle ICS ciclesonide on an even less invasive marker of small airway inflammation, i.e. alveolar eNO. This is an interesting finding since alveolar eNO is an easy to measure, noninvasive parameter that is preferable to CT scanning or transbronchial biopsies for clinical follow-up of small airway inflammation.

A possible limitation of the present CT methodology may be the lack of spirometric gating. Therefore, theoretically, one can never be entirely sure that end-expiratory lung volume is not affected by things such as an incomplete expiration, and thus the lack of spirometric gating may affect reproducibility of the measurements. Nevertheless, other studies that also do not apply spirometric gating have demonstrated that air trapping on HRCT is significantly associated with spirometric indices of global and peripheral airway obstruction [24]. This indicates that even without spirometric gating, CT scanning is still very sensitive in assessing small airways disease in asthma. Although spirometric gating is of value when measuring air trapping on a baseline expiratory scan, the use of spirometric gating in assessing $\mathrm{MCh}$-induced air trapping in asthma could be questioned. Due to $\mathrm{MCh}$-induced air trapping, lung inflation may occur and residual volume may increase, thereby affecting the trigger to scan. The subjects in the present study were trained in order to perform maximal inspiration and maximal expiration correctly and the inspiratory/expiratory manoeuvres were closely observed during scanning. Scans were only acquired when inspiratory/expiratory manoeuvres were technically satisfactory. 

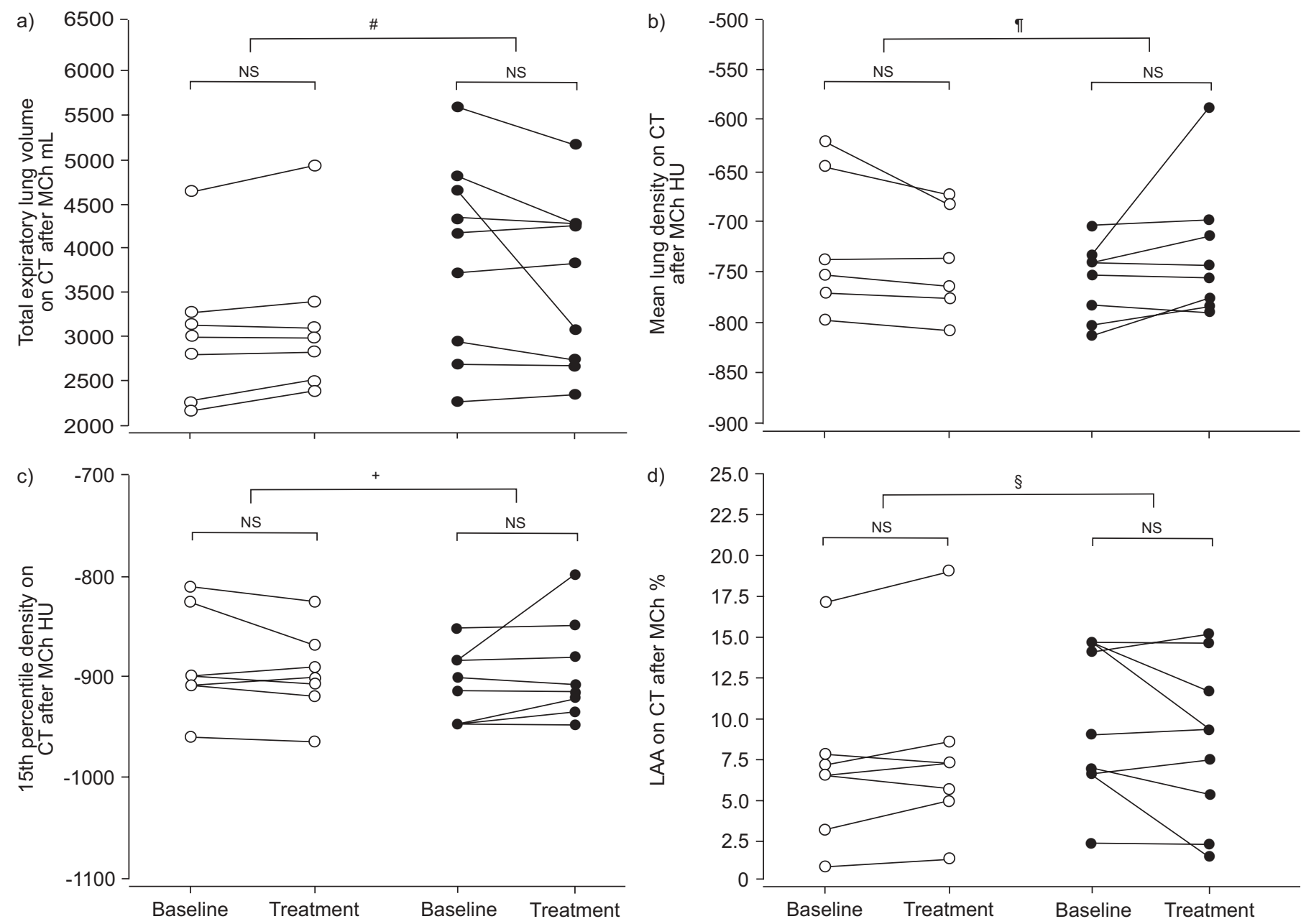

FIGURE 3. Methacholine (MCh)-induced air trapping on computed tomography (CT) scans. MCh-induced air trapping on CT before and after treatment with placebo $(\bigcirc)$ and ciclesonide $(\bullet)$. a) Total expiratory lung volume after MCh; b) mean lung density after MCh; c) 15th percentile density after MCh; and d) percentage low attenuation areas (LAA) after MCh. \#: $p=0.042 ;{ }^{\bullet}: p=0.016 ;^{+}: p=0.023 ;$ s: $^{\circ}=0.055$. All p-values from Mann-Whitney U-test.

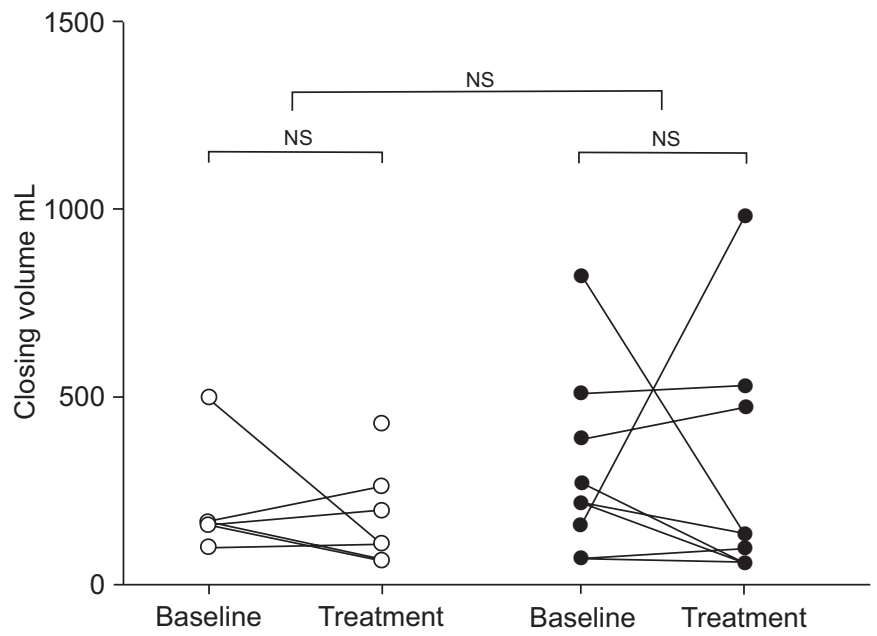

FIGURE 4. Closing volume with the single-breath nitrogen test after treatment with placebo $(\bigcirc)$ and ciclesonide
). NS: nonsignificant.
One of the pitfalls of small airway research in asthma is the absence of a gold standard to compare small airway function and or inflammation to. Nevertheless, all tests used in the present study have been extensively investigated and suggested by other research groups as adequate parameters to reflect functioning of the small airways, which justifies the choice of these tests [21, 25, 28, 29, 41]. Furthermore, the finding in the present study that a small-particle ICS improves small airway parameters in a small number of asthmatics, in contrast with placebo, provides a sound basis for the validity of these parameters.

Why would ciclesonide significantly improve alveolar eNO and MCh-induced air trapping on expiratory CT but not the other small airway parameters evaluated? First, some of the small airway parameters tested had a large variability (table 2), thus reducing statistical power. A formal power calculation was not performed in this pilot study as effect sizes of small airway parameters were unknown when the study was designed. Nevertheless, it is reassuring that other intervention studies 
providing positive effects of small-particle ICS have used similar sample sizes [38, 42,43]. Secondly, the lack of improvement in closing volume after ciclesonide treatment does not rule out a beneficial effect on small airway closure, as SVC improved in the present patients; therefore, closing capacity may have been a better measure than closing volume. However, this could not be examined due to the lack of lung volume measurements. Another explanation for the results may be that the tested small airway parameters do not all measure the same aspects of small airway disease. KING and co-workers [44, 45] described that closing volumes measured using the $\mathrm{SBN}_{2}$ test can differ greatly between two individuals who have a similar extent of airway closure and air trapping on a CT scan, because the $\mathrm{SBN}_{2}$ test detects airway closure during expiration at a lung volume that is different from the end-expiratory lung volume. VAN VEEN et al. [21] described that $\triangle \mathrm{FVC}$ at PC20 of MCh was not associated with alveolar eNO in contrast to other measures of peripheral airway dysfunction. The present authors conclude that future studies are needed in order to determine which is the best tool to monitor small airway improvements; for now, eNO and expiratory CT scanning are promising.

Seven subjects underwent a bronchoscopy at baseline and after treatment during which ELF from central and peripheral airways was sampled with microsampling probes. Half of all sampled probes were contaminated with blood from bronchial mucosa. The present authors conclude that it is not feasible to sample ELF from peripheral airways in clinical studies investigating asthma patients, in contrast to successful application in acute respiratory distress syndrome and COPD [31, 32].

In summary, the present study has demonstrated that treatment with the small-particle inhaled corticosteroid ciclesonide, at a once daily dose of $320 \mu \mathrm{g}$, improves alveolar exhaled nitric oxide and methacholine-induced air trapping on expiratory computed tomography scan in patients with mild-to-moderate asthma. The present findings suggest that alveolar exhaled nitric oxide is a useful tool to assist in diagnosing and monitoring small airway pathology in asthma, since it is already sensitive to changes in a small number of patients. It has already been demonstrated that ciclesonide reaches the small airways [8], and the present study provides evidence, for the first time, that ciclesonide exerts anti-inflammatory effects at this site.

\section{ACKNOWLEDGEMENTS}

The authors would like to thank M. Farenhorst, J. Bruins-Slot, K. Vink-Klooster, M. Swierenga and S. Alberts-Poots from the Lung Function Laboratory for performing all lung function tests, W. Tukker from the Dept of Radiology for acquiring the computed tomography scans, A. Smidt from the Dept of Endoscopy for assistance during bronchoscopy, B. Dijkhuizen and A. van Oosterhout from the Laboratory of Allergology and Pulmonary Diseases for analysing the microsampling probes (all University of Groningen, Groningen, the Netherlands), and C. Hilck, S. Zentis, V. Dicken and J-M. Kuhnigk from MeVis Diagnostic Systems (Bremen, Germany) for post-processing computed tomography scans

\section{REFERENCES}

1 Bellamy D, Harris T. Poor perceptions and expectations of asthma control: results of the International Control of
Asthma Symptoms (ICAS) survey of patients and general practitioners. Prim Care Respir J 2005; 14: 252-258.

2 Rabe KF, Vermeire PA, Soriano JB, Maier WC. Clinical management of asthma in 1999: the Asthma Insights and Reality in Europe (AIRE) study. Eur Respir J 2000; 16: 802-807.

3 Carlton BG, Lucas DO, Ellis EF, Conboy-Ellis K, Shoheiber O, Stempel DA. The status of asthma control and asthma prescribing practices in the United States: results of a large prospective asthma control survey of primary care practices. J Asthma 2005; 42: 529-535.

4 Leach CL. Improved delivery of inhaled steroids to the large and small airways. Respir Med 1998; 92: Suppl. A, 3-8.

5 Mead J, Takishima T, Leith D. Stress distribution in lungs: a model of pulmonary elasticity. J Appl Physiol 1970; 28: 596-608.

6 Woolcock AJ. Effect of drugs on small airways. Am J Respir Crit Care Med 1998; 157: S203-S207.

7 Balzar S, Wenzel SE, Chu HW. Transbronchial biopsy as a tool to evaluate small airways in asthma. Eur Respir J 2002; 20: 254-259.

8 Newman S, Salmon A, Nave R, Drollmann A. High lung deposition of $99 \mathrm{mTc}$-labeled ciclesonide administered via HFA-MDI to patients with asthma. Respir Med 2006; 100: 375-384.

9 Chapman KR, Patel P, D'Urzo AD, et al. Maintenance of asthma control by once-daily inhaled ciclesonide in adults with persistent asthma. Allergy 2005; 60: 330-337.

10 Berger WE. Ciclesonide: a novel inhaled corticosteroid for the treatment of persistent asthma - a pharmacological and clinical profile. Therapy 2005; 2: 167-178.

11 Lee DK, Haggart K, Currie GP, Bates CE, Lipworth BJ. Effects of hydrofluoroalkane formulations of ciclesonide 400 microg once daily vs fluticasone 250 microg twice daily on methacholine hyper-responsiveness in mild-tomoderate persistent asthma. Br J Clin Pharmacol 2004; 58: 26-33.

12 Derom E, Van De Velde V, Marissens S, Engelstätter R, Vincken W, Pauwels R. Effects of inhaled ciclesonide and fluticasone propionate on cortisol secretion and airway responsiveness to adenosine 5'monophosphate in asthmatic patients. Pulm Pharmacol Ther 2005; 18: 328-336.

13 Kanniess F, Richter K, Böhme S, Jörres RA, Magnussen H. Effect of inhaled ciclesonide on airway responsiveness to inhaled AMP, the composition of induced sputum and exhaled nitric oxide in patients with mild asthma. Pulm Pharmacol Ther 2001; 14: 141-147.

14 Taylor DA, Jensen MW, Kanabar V, et al. A dosedependent effect of the novel inhaled corticosteroid ciclesonide on airway responsiveness to adenosine- 5 monophosphate in asthmatic patients. Am J Respir Crit Care Med 1999; 160: 237-243.

15 Leung SY, Eynott P, Nath P, Chung KF. Effects of ciclesonide and fluticasone propionate on allergen-induced airway inflammation and remodeling features. I Allergy Clin Immunol 2005; 115: 989-996.

16 Wilson AM, Duong M, Pratt B, Dolovich M, O’Byrne PM. Anti-inflammatory effects of once daily low dose inhaled ciclesonide in mild to moderate asthmatic patients. Allergy 2006; 61: 537-542. 
17 Zietkowski Z, Bodzenta-Lukaszyk A, Tomasiak MM, Szymanski W, Skiepko R. Effect of ciclesonide and fluticasone on exhaled nitric oxide in patients with mild allergic asthma. Respir Med 2006; 100: 1651-1656.

18 Global initiative for asthma. Global strategy for asthma management and prevention. Bethesda/Maryland: NHLBI/WHO workshop report, 1995. National Institutes of Health and National Heart Lung and Blood Institute. 1995.

19 Quanjer PH, Tammeling GJ, Cotes JE, Pedersen OF, Peslin R, Yernault JC. Lung volumes and forced ventilatory flows. Report Working Party Standardization of Lung Function Tests, European Community for Steel and Coal. Official Statement of the European Respiratory Society. Eur Respir J 1993; 6: Suppl. 16, 5-40.

20 Recommendations for standardized procedures for the online and off-line measurement of exhaled lower respiratory nitric oxide and nasal nitric oxide in adults and children 1999. This official statement of the American Thoracic Society was adopted by the ATS Board of Directors, July 1999. Am J Respir Crit Care Med 1999; 160: 2104-2117.

21 van Veen IH, Sterk PJ, Schot R, Gauw SA, Rabe KF, Bel EH. Alveolar nitric oxide versus measures of peripheral airway dysfunction in severe asthma. Eur Respir J 2006; 27: 951-956.

22 Rottier BL, Cohen J, van der Mark TW, Douma WR, Duiverman EJ, ten Hacken NH. A different analysis applied to a mathematical model on output of exhaled nitric oxide. J Appl Physiol 2005; 99: 378-379.

23 Zeidler MR, Kleerup EC, Goldin JG, et al. Montelukast improves regional air-trapping due to small airways obstruction in asthma. Eur Respir J 2006; 27: 307-315.

24 Ueda T, Niimi A, Matsumoto H, et al. Role of small airways in asthma: investigation using high-resolution computed tomography. J Allergy Clin Immunol 2006; 118: 1019-1025.

25 Goldin JG, McNitt-Gray MF, Sorenson SM, et al. Airway hyperreactivity: assessment with helical thin-section CT. Radiology 1998; 208: 321-329.

26 McFadden ER Jr, Holmes B, Kiker R. Variability of closing volume measurements in normal man. Am Rev Respir Dis 1975; 111: 135-140.

27 Bourdin A, Paganin F, Préfaut C, Kieseler D, Godard P, Chanez P. Nitrogen washout slope in poorly controlled asthma. Allergy 2006; 61: 85-89.

28 Abisheganaden J, Chan CC, Chee CB, Wang YT. Methacholine-induced fall in forced vital capacity as a marker of asthma severity. Respir Med 1999; 93: 277-282.

29 Gibbons WJ, Sharma A, Lougheed D, Macklem PT. Detection of excessive bronchoconstriction in asthma. Am J Respir Crit Care Med 1996; 153: 582-589.

30 Sterk PJ, Fabbri LM, Quanjer PH, et al. Airway responsiveness. Standardized challenge testing with pharmacological, physical and sensitizing stimuli in adults. Report Working Party Standardization of Lung Function Tests, European Community for Steel and Coal. Official Statement of the European Respiratory Society. Eur Respir J 1993; 6: Suppl. 16, 53-83.

31 Ishizaka A, Watanabe M, Yamashita $T$, et al. New bronchoscopic microsample probe to measure the biochemical constituents in epithelial lining fluid of patients with acute respiratory distress syndrome. Crit Care Med 2001; 29: 896-898.

32 Komaki Y, Sugiura H, Koarai A, et al. Cytokine-mediated xanthine oxidase upregulation in chronic obstructive pulmonary disease's airways. Pulm Pharmacol Ther 2005; 18: 297-302.

33 Niphadkar P, Jagannath K, Joshi JM, et al. Comparison of the efficacy of ciclesonide 160 microg QD and budesonide 200 microg BID in adults with persistent asthma: a phase III, randomized, double-dummy, open-label study. Clin Ther 2005; 27: 1752-1763.

34 Postma DS, Sevette C, Martinat Y, Schlösser N, Aumann J, Kafé $H$. Treatment of asthma by the inhaled corticosteroid ciclesonide given either in the morning or evening. Eur Respir J 2001; 17: 1083-1088.

35 Buhl R, Vinkler I, Magyar P, et al. Comparable efficacy of ciclesonide once daily versus fluticasone propionate twice daily in asthma. Pulm Pharmacol Ther 2006; 19: 404-412.

36 Pearlman DS, Berger WE, Kerwin E, Laforce C, Kundu S, Banerji D. Once-daily ciclesonide improves lung function and is well tolerated by patients with mild-to-moderate persistent asthma. J Allergy Clin Immunol 2005; 116: 1206-1212.

37 Verbanck S, Schuermans D, Paiva M, Vincken W. The functional benefit of anti-inflammatory aerosols in the lung periphery. J Allergy Clin Immunol 2006; 118: 340-346.

38 Hauber HP, Gotfried M, Newman K, et al. Effect of HFAflunisolide on peripheral lung inflammation in asthma. J Allergy Clin Immunol 2003; 112: 58-63.

39 Bergeron C, Hauber HP, Gotfried M, et al. Evidence of remodeling in peripheral airways of patients with mild to moderate asthma: effect of hydrofluoroalkane-flunisolide. J Allergy Clin Immunol 2005; 116: 983-989.

40 Goldin JG, Tashkin DP, Kleerup EC, et al. Comparative effects of hydrofluoroalkane and chlorofluorocarbon beclomethasone dipropionate inhalation on small airways: assessment with functional helical thin-section computed tomography. J Allergy Clin Immunol 1999; 104: S258-S267.

41 Sutherland ER, Martin RJ, Bowler RP, Zhang Y, Rex MD, Kraft M. Physiologic correlates of distal lung inflammation in asthma. J Allergy Clin Immunol 2004; 113: 1046-1050.

42 Fardon TC, Burns P, Barnes ML, Lipworth BJ. A comparison of 2 extrafine hydrofluoroalkane-134abeclomethasone formulations on methacholine hyperresponsiveness. Ann Allergy Asthma Immunol 2006; 96: 422-430.

43 Horiguchi T, Hayashi N, Ohira D, et al. Usefulness of HFABDP for adult patients with bronchial asthma: randomized crossover study with fluticasone. J Asthma 2006; 43: 509-512.

44 King GG, Downie SR, Verbanck S, et al. Effects of methacholine on small airway function measured by forced oscillation technique and multiple breath nitrogen washout in normal subjects. Respir Physiol Neurobiol 2005; 148: 165-177.

45 King GG, Salome CM. Multimodality measurements of small airways disease. Eur Respir J 2006; 27: 250-252. 